\title{
GESTÃO ESTRATÉGICA PARA O DESENVOLVIMENTO SUSTENTÁVEL DE FLORESTAS PLANTADAS - ESTUDO APLICADO EM DOIS VIZINHOS, PARANÁ, BRASIL ${ }^{1}$
}

\author{
STRATEGIC MANAGEMENT FOR SUSTAINABLE DEVELOPMENT OF \\ PLANT FORESTS - APPLIED STUDY TO DOIS VIZINHOS, PARANÁ, BRAZIL
}

\author{
Charles Costa Coelho ${ }^{2}$, Bruna Pereira ${ }^{3}$, Eleandro José Brun ${ }^{4}$, \\ Maria Madalena Santo da Silva ${ }^{5}$ Flavia Gizele Konig Brun ${ }^{6}$
}

\section{RESUMO}

O propósito do trabalho foi avaliar variáveis quantitativas relacionadas às áreas plantadas e com potencial para novos plantios florestais, visando a criação de estratégias para o crescimento da cadeia produtiva de base florestal no município de Dois Vizinhos-Paraná. Com base em análise de imagem de satélite e avaliações in loco, foram estudadas todas as áreas e suas variáveis associadas. O município apresenta uma proporção maior de Área Potencial (AP), com 1.407,4 ha, sendo 0,98\% maior do que a área de Floresta Plantada (FP) com 996,4 ha, em relação à área total do município. A classe FP-Eucalipto apresenta maior extensão de área, com 879,9 ha, seguido de FP-Pinus (80,4 ha) e FP-Erva-mate (36,1 ha). Na Classe AP, a que mais se destacou foi pastagem degradada (811,7 ha), seguida de AP-Capoeira (552,1 ha) e AP-Lavoura degradada (42,8 ha). Os produtores vêm investindo no setor florestal nos últimos anos, com grande foco em eucalipto, movido principalmente pelas agroindústrias regionais que demandam aporte de biomassa energética. Há um déficit de matéria prima para usos com maior valor agregado, sendo imprescindível a ampliação do potencial de fornecimento de madeira para estes e outros setores nos próximos anos.

Palavras-chave: Avaliação, Eucalipto, Implantação florestal, Madeira, Pastagem degradada.

\section{ABSTRACT}

The purpose of this work was to evaluate quantitative variables related to the planted areas and potential for new forest plantations, aiming the tracing of strategies for the growth of forest-based productive chain in the municipality of Dois Vizinhos-Paraná. Based on satellite image analysis and on-site assessments, all areas and their associated variables were evaluated. The municipality has a great proportion of Potential Area (PA) with 1,407.4 ha, which is $0.98 \%$ higher than the Planted Forest (PF) area with 996.4 ha, in relation to the total area of the municipality. The PF-Eucalyptus class has the highest amount of area, with 879.9 ha, followed by PF-Pinus $(80.4 \mathrm{ha})$ and FP-Mate $(36.1 \mathrm{ha})$. In the PA class, degraded pasture $(811.7 \mathrm{ha})$ was the most outstanding, followed by PA-Capoeira (552.1 ha) and degraded PA-Tillage (42.8 ha). Recently, the producers have been investing in the forestry sector, with focus on eucalyptus, mainly driven by regional agroindustries,

1 Trabalho realizado com apoio do Ministério da Educação (MEC) (Edital Proext 2014).

2 Engenheiro Florestal, Msc. CTO e Diretor de P\&D da Arboran - Soluções em Arborização Urbana. E-mail: ccoelho.florestal@gmail.com

3 Engenheira Florestal na empresa Conífera Engenharia. E-mail: brunap903@gmail.com

4 Eng. Ftal., Dr., Professor - Curso de Engenharia Florestal e Programa de Pós-graduação em Agroecossistemas da UTFPR Campus Dois Vizinhos. E-mail: eleandrobrun@utfpr.edu.br

5 Eng. Cart., Dra., Professora do Curso de Engenharia Florestal da UTFPR Campus Dois Vizinhos. E-mail: mariasantos@, utfpr.edu.br

6 Eng. Ftal., Dra., Professora do Curso de Engenharia Florestal da UTFPR Campus Dois Vizinhos. E-mail: flaviag@utfpredu.br. 
which demand energy biomass input. With a deficit of raw material for higher value-added uses, it is essential the expansion of wood supply potential for these and other sectors in coming years.

Keywords: Evaluation, Eucalyptus, Forest implantation, Wood, Degraded pasture.

\section{INTRODUÇÃO}

A pressão ambiental exercida pela exploração de florestas nativas como fonte de matéria prima, tendo como forte contraponto uma legislação ambiental bastante restritiva, abriu oportunidades de negócios nos plantios florestais de espécies exóticas, as quais se tornaram importantes alternativas no fornecimento de matéria prima para a confecção de inúmeros produtos de madeira, ao mesmo tempo as tornando ferramentas de proteção ambiental contra o desmatamento das florestas nativas (SOUZA et al., 2012; SCHUMACHER et al., 2013; COUTINHO et al., 2017 ).

No Brasil, a atividade florestal exerce um papel importante, não só pela extensa cobertura de florestas existente no País, mas também pela capacidade de geração de emprego e renda do setor. Dados da Indústria Brasileira de Árvores (IBÁ, 2020) indicam que, em 2019, o produto interno bruto (PIB) florestal brasileiro atingiu R \$ 97,4 bilhões, representando 1,2\% do PIB Nacional e 6,3\% da indústria, com a geração de 3,75 milhões de empregos diretos e indiretos, e que até 2023 deverá criar mais de 23 mil novos empregos.

Para Juvenal e Grion (2002), as condições edafoclimáticas para a silvicultura brasileira conferem grandes vantagens no cultivo de plantios florestais. Essas condições, aliados ao desenvolvimento tecnológico no plantio, condução, manejo, colheita de florestas, bem como a sua posterior industrialização, transformam as vantagens naturais em competitividade real (TATAGIBA et al., 2015).

Um fator importante que favorece a utilização de florestas plantadas é a tendência mundial de expansão dos mercados para a "madeira ambientalmente correta", ou seja, certificada com o chamado "selo verde". Aliando todos esses fatores com a globalização dos mercados consumidores, tem-se uma crescente necessidade de aumento na produtividade e de atendimento de padrões de qualidade cada vez mais exigentes, estimulando a exploração da madeira de espécies exóticas (SOUZA et al., 2012; TREVISAN, 2010).

Nos últimos anos o setor florestal brasileiro destacou-se como um dos mais importantes no cenário global, com 7,8 milhões de hectares de árvores plantadas, sendo 91\% de toda a madeira produzida para fins industriais (IBÁ, 2018). O Paraná é o estado com a sexta maior área plantada com Eucalyptus, cujos povoamentos cobrem uma superfície de 1,3\% do estado, tendo a maior concentração na região Centro-Sul, com aproximadamente 255.845 ha (25,4\% da área florestal plantada), sendo que a maior parte da matéria-prima está comprometida com empresas florestais regionais, principalmente de celulose e papel e indústrias de painéis de madeira (APRE, 2020).

O desenvolvimento do setor de florestas plantadas também deve ter foco nas pequenas áreas e pequenos municípios brasileiros, mesmo aqueles fora de regiões tradicionalmente produtoras de 
madeira e outros produtos florestais não madeireiros, fato que é um desafio que se impõe a todos os envolvidos com este setor, para os próximos anos, desde as empresas, órgãos de extensão e pesquisa e universidades, uma vez que projetos estruturantes e de longo prazo precisam ser executados de forma a levar a todo o pequeno proprietário rural, o nível tecnológico e de rentabilidade hoje aplicado em empresas do setor.

Assim, este trabalho teve por objetivo estudar variáveis quantitativas de áreas plantadas e áreas potenciais para novos plantios florestais, visando o traçamento de estratégias para o crescimento da cadeia produtiva de base florestal no município de Dois Vizinhos-Paraná.

\section{MATERIAL E MÉTODOS}

\section{ÁREA DE ESTUDO}

O trabalho foi realizado no município de Dois Vizinhos, localizado na região Sudoeste do Paraná (Figura 1). Segundo a classificação de Köppen, o clima é classificado como subtropical úmido mesotérmico (Cfa), com verão quente, sem estação seca, com temperatura do mês mais quente de $22^{\circ} \mathrm{C}$ e temperatura média anual de $18,4^{\circ} \mathrm{C}$. A precipitação média varia entre $1.900-2.200 \mathrm{~mm} / \mathrm{ano}$ (ALVARES et al., 2017).

Figura 1 - Localização da área de estudo, município de Dois Vizinhos no estado do Paraná - BR.
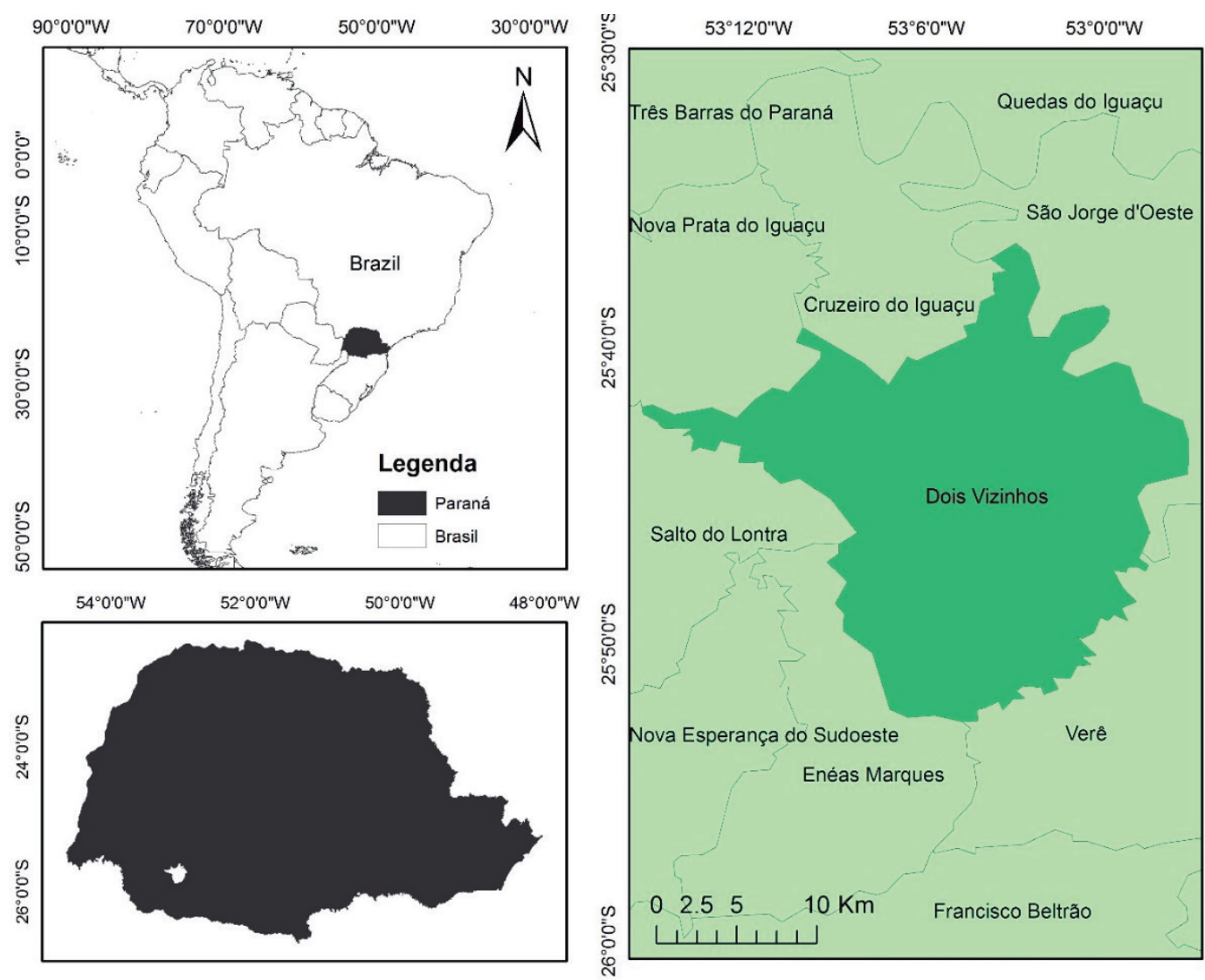
Os solos encontrados no município são classificados, predominantemente, como: Latossolos, Argissolos, Cambissolos e Neossolos Litólicos (MAAK, 1968; PIGOSSO et al., 2009; MOTA, 2015). Os Latossolos são considerados solos profundos e bem drenados, pouco férteis, semelhante aos Argissolos, solos profundos e de baixa fertilidade, diferindo da classe dos Cambissolos, que apresentam baixa profundidade e cascalho, solo que pode ser susceptível à erosão, porém apresenta bons níveis de matéria orgânica. Por último, os Neossolos Litólicos apresentam boa fertilidade, porém sendo solos novos e rasos, com pouca profundidade (SANTOS et al., 2018).

Dois Vizinhos está localizado em um ecótono entre duas fitofisionomias florestais, com o encontro da Floresta Ombrófila Mista e Floresta Estacional Semidecidual, uma região que apresenta notável desmatamento histórico, justamente por apresentar espécies com alto valor econômico como, por exemplo: Aspidosperma polyneuron Müll. Arg., Cedrela fissilis Vell, Ocotea porosa (Nees \& Mart.) Barroso e Araucaria angustifolia (Bert.) Kuntze (GORENSTEIN et al., 2010), assim como uma região com solo e clima favoráveis à agropecuária.

O município é considerado a "Capital Nacional do Frango", devido a uma concentração de indústrias frigoríficas, gerando empregos direta e indiretamente ao município e região (PORTAL DOIS VIZINHOS, 2017). O município apresenta 1.934 propriedades rurais, com uma área média de 16,7 ha cada (IBGE, 2018), sendo a grande maioria considerada como pequena propriedade rural.

A necessidade do uso de madeira na produção avícola da região encontra-se basicamente em todas as fases da produção, principalmente como matéria prima para a composição da cama das aves na forma de maravalha e, como destaque, na produção de biomassa para energia, usada na calefação dos aviários e também nas caldeiras das agroindústrias. No ano de 2014, o consumo total de madeira para energia no município foi de $408 \mathrm{mil} \mathrm{m}^{3}$ (BRUN, 2016).

\section{METODOLOGIA DE TRABALHO}

Para a realização do estudo foi utilizado imagem do satélite Pleiades, imagens referentes ao ano de 2014, com resolução de 0,5 m, adquirida pela Universidade Tecnológica Federal do Paraná Campus Dois Vizinhos, com apoio do Ministério da Educação (Edital PROEXT 2014). Inicialmente, realizou-se um trabalho de análise da imagem, pelo método de interpretação visual, além de embasamento em literatura e do conhecimento prévio da realidade do município, de forma a definir as classes a serem utilizadas no trabalho, com foco no objetivo inicialmente proposto.

Com auxílio do programa ArcGIS versão 10.4, no ArcCatalog, foram realizados os procedimentos para criação dos arquivos shapes de polígono. Assim, foram criadas as seguintes classes: Florestas Plantadas (FP), sendo estas separadas em: FP-Eucalipto; FP-Erva-mate; FP-Pinus e também Áreas potenciais de plantio (AP), sendo estas separadas em: AP-Lavoura degradada; AP-Pastagem degradada e AP-Capoeira (Floresta nativa em estágio inicial de regeneração - Com base na Resolução 
CONAMA 02/1994). Cada classe, representou um shape. Após a definição das classes, executou-se a vetorização e a criação de um ponto de referência no centro da cidade, para que fosse possível criar raios de distância em direção ao interior do município, de forma a ser base de planejamento logístico para a cadeia produtiva florestal (Shape de ponto). Os raios de distância foram criados utilizando um buffer, com raios de 5, 10, 15 e $20 \mathrm{~km}$. O processamento e análise dos dados de natureza quantitativa foram realizados via planilha Microsoft Excel ${ }^{\circledR}$, bem como a construção de tabelas para apresentação dos resultados.

A classe Floresta Plantada foi identificada em função das características de alinhamento de plantio, arquitetura da copa e coloração uniforme. Pode-se dizer que é relativamente fácil a diferenciação de florestas nativas das florestas plantadas, que por sua vez, floresta nativa apresenta uma dispersão heterogênea, diferindo da floresta plantada, que é mais homogênea (PAIVA et al., 2011; HENTZ, 2018). De forma geral, para florestas de Pinus sp., a coloração foi o padrão mais presente, onde o predomínio da cor vermelho-claro indicava um plantio jovem, e para cor vinho, plantios maduros. Para florestas de Eucalyptus sp., a arquitetura do dossel e a coloração verde-claro, indicava plantio da espécie, e por fim, para os plantios de Erva-mate (Ilex paraguariensis A. St. Hil.), plantios heterogêneos abertos e plantios homogêneos com copa dos indivíduos no formato circular, e de coloração verde-escuro, indicavam plantios da espécie.

As áreas potenciais de plantio foram classificadas pela presença de sinais aparentes de degradação ambiental, tais como presença de erosão hídrica (sulcos e voçorocas), manchas de solo descoberto, áreas com declividade elevada, manchas com coloração diferenciada na folhagem da vegetação (indicando deficiência nutricional aparente das plantas). As áreas que ainda se encontravam em uso como lavoura, mesmo nas citadas condições precárias, eram classificadas conforme seu uso (AP - Lavoura degradada e AP-Pastagem degradada), porém, as áreas que se encontravam sob condição de abandono, não sendo possível definir seu uso anterior, se lavoura ou pastagem, eram classificadas como capoeira, entendida como uma área em situação intermediária entre uma área em uso (pastagem ou lavoura) e uma floresta em estágio inicial de regeneração. Os pontos classificados como duvidosos, os quais não era possível ter clareza de qual classe pertencia, eram tomadas as coordenadas e inseridas em GPS de navegação, sendo realizadas incursões a campo para uma classificação adequada in loco.

\section{RESULTADOS E DISCUSSÃO}

O município apresentou uma proporção maior de Área Potencial (AP), com 1.407,38 ha, o que, em termos relativos à área total do município, é 0,98\% maior do que a Floresta Plantada (FP), que tem 996,35 ha. Este montante de área potencial, comparado especificamente com a área já plantada, é 41,2\% superior (Tabela 1). De acordo com dados fornecidos pela Associação Empresarial de Dois Vizinhos-PR (ACEDV), existem em torno de 151 empresas que possuem algum envolvimento com 
o ramo florestal, assim, o município apresenta alto potencial para o aumento de plantio dessas áreas, atendendo toda a demanda existente no município e região.

Tabela 1 - Dados quantitativos separados por categoria na área de estudo.

\begin{tabular}{ccc}
\hline Classe & Área (ha) & Ocorrência relativa (\%) * \\
\hline Floresta Plantada - FP & 996,4 & 2,38 \\
Área Potencial - AP & $1.407,4$ & 3,36 \\
\hline Total & $2.403,7$ & 5,74 \\
\hline Legenda: * Porcentagem em relação à área total do município
\end{tabular}

Segundo estudos realizados por Brun (2016), o consumo semanal estimado de lenha no município de Dois Vizinhos, é de $7.858,7 \mathrm{~m}^{\text {st }}$ (cerca de $5613,4 \mathrm{~m}^{3}$ ) sendo a agroindústria a principal consumidora desse produto (77,6\%). Mesmo com a ampliação da área plantada para 2.403,73 ha, considerando uma rotação média de sete anos, o déficit de madeira para o suprimento da demanda de Dois Vizinhos ainda continuaria elevado, uma vez que o consumo, em sete anos, seria de 6.300 ha, contra somente 2.403,73 ha de plantio, o que significa um déficit de 3.896,3 ha, o que deve ser suprido pelos plantios existentes na região de entorno, fazendo com que o município também tenha o potencial de alavancar a cadeia produtiva de base florestal na sua microrregião.

Porém, considerando que Dois Vizinhos possui cerca de 31 mil ha de área em condição efetiva de uso agropecuário, o que alcança cerca de $74 \%$ da área total do município $\left(418,2 \mathrm{~km}^{2}\right)$, seria possível que o atendimento de toda a demanda de biomassa energética ocorresse dentro do território municipal. Para isso, a implementação de sistemas agroflorestais e agrosilvipastoris seria algo essencial, integrando a produção florestal com a agricultura e pecuária.

É possível observar que a classe FP - Eucalipto apresentou maior quantidade de área, com 879,89 ha, seguido de FP-Pinus (80,40 ha) e FP-Erva-mate (36,06 ha). Já na Classe AP, a que mais se destacou foi pastagem degradada (811,69 ha), seguida de AP-Capoeira (552,11 ha) e AP- Lavoura degrada (42,75 ha) (Tabela 2).

Tabela 2 - Dados quantitativos separados por classes avaliadas. Dois Vizinhos (PR).

\begin{tabular}{lcc}
\hline Classe & ha & $\mathbf{\%} *$ \\
\hline FP - Pinus (ha) & 80,4 & 0,19 \\
\hline FP- Eucalipto (ha) & 879,9 & 2,10 \\
\hline FP - Erva-Mate (ha) & 36,0 & 0,08 \\
AP - Capoeira (ha) & 552,9 & 1,32 \\
AP - Pastagem Degradada (ha) & 811,7 & 1,94 \\
AP - Lavoura Degradada (ha) & 42,6 & 0,10 \\
Total & $2.403,7$ & 5,74 \\
\hline
\end{tabular}

* Porcentagem encontrada sobre a área total do município em relação à classe. 
De acordo com o trabalho realizado por Eisfeld e Nascimento (2015) sobre o Mapeamento dos Plantios Florestais do Estado do Paraná - Pinus e Eucalyptus, são relatados, para Dois Vizinhos-PR, 68,10 ha de pinus e 650,30 ha de eucalipto. Cabe ressaltar que o trabalho desses autores, apesar de ter sido executado, temporalmente, no mesmo período (base de dados de 2012-2014), considerou plantios com alguma vinculação direta a empresas da área ou usuárias de madeira, sem contar os plantios existentes nas pequenas propriedades rurais de forma independente, sem essa vinculação direta.

As florestas plantadas (pinus, eucalipto e erva-mate) encontram-se distribuídas, dentro do território municipal, com uma grande quantidade de área plantada próximo da área urbana (Figura 2), a qual pertence a uma empresa privada do ramo alimentício, que utiliza a matéria prima para produção de biomassa. Fora isso, os demais plantios têm distribuição ampla em todo o município, entremeando propriedades rurais diversas.

Figura 2 - Distribuição de área plantada (Pinus, Eucalipto e Erva-mate), no município de Dois Vizinhos (PR).

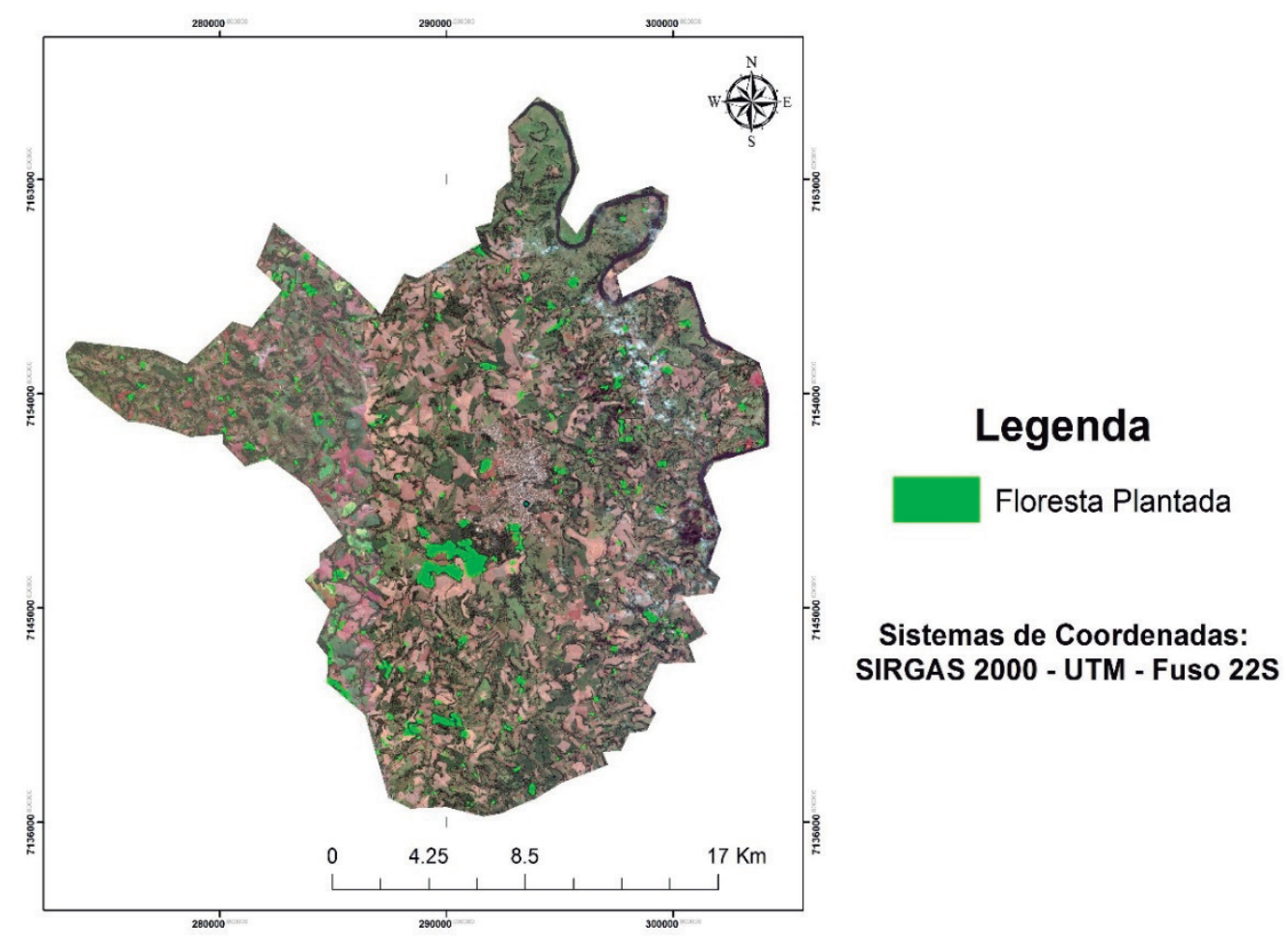

A proximidade entre proprietários e a empresa faz com que os micros e os pequenos sejam as classes de proprietários com maior interesse em permanecer na atividade florestal, fato que se deve, em grande parte, pelo apoio e pelos lucros com a atividade, visto que o mercado está em demanda constante por madeira proveniente de reflorestamentos (ROCHADELLI et al., 2008; BICHEL, et al., 2014).

Entretanto, quando se tratam de áreas potenciais para novos plantios (Figura 3), observa-se uma distribuição inversa, com a maioria das AP (capoeira, pastagem e lavoura degradada) em localizações mais distantes da área urbana, próximas do limite territorial do município. Segundo informações da Indústria Brasileira de árvores - IBÁ (2016), visando não só o retorno financeiro, mas 
também os aspectos ecológicos da área, a Integração Lavoura Pecuária e Floresta (ILPF) entra como uma peça chave no processo de recuperação de pastagem e lavoura degradadas, além de poder diversificar a receita do produtor, e ao mesmo tempo contribui para o setor florestal. Por isso, acredita-se que a inserção do componente florestal, em muitas propriedades rurais, como as produtoras de leite, em grande número no município, deverá se dar através dos sistemas de integração, com a inserção de árvores em meio a pastagens já existentes ou mesmo a implantação de sistemas completos com árvores, pastagens e animais de produção.

Figura 3 - Distribuição de área potencial (Capoeira, Lavoura e Pastagem degradada), no município de Dois Vizinhos (PR).

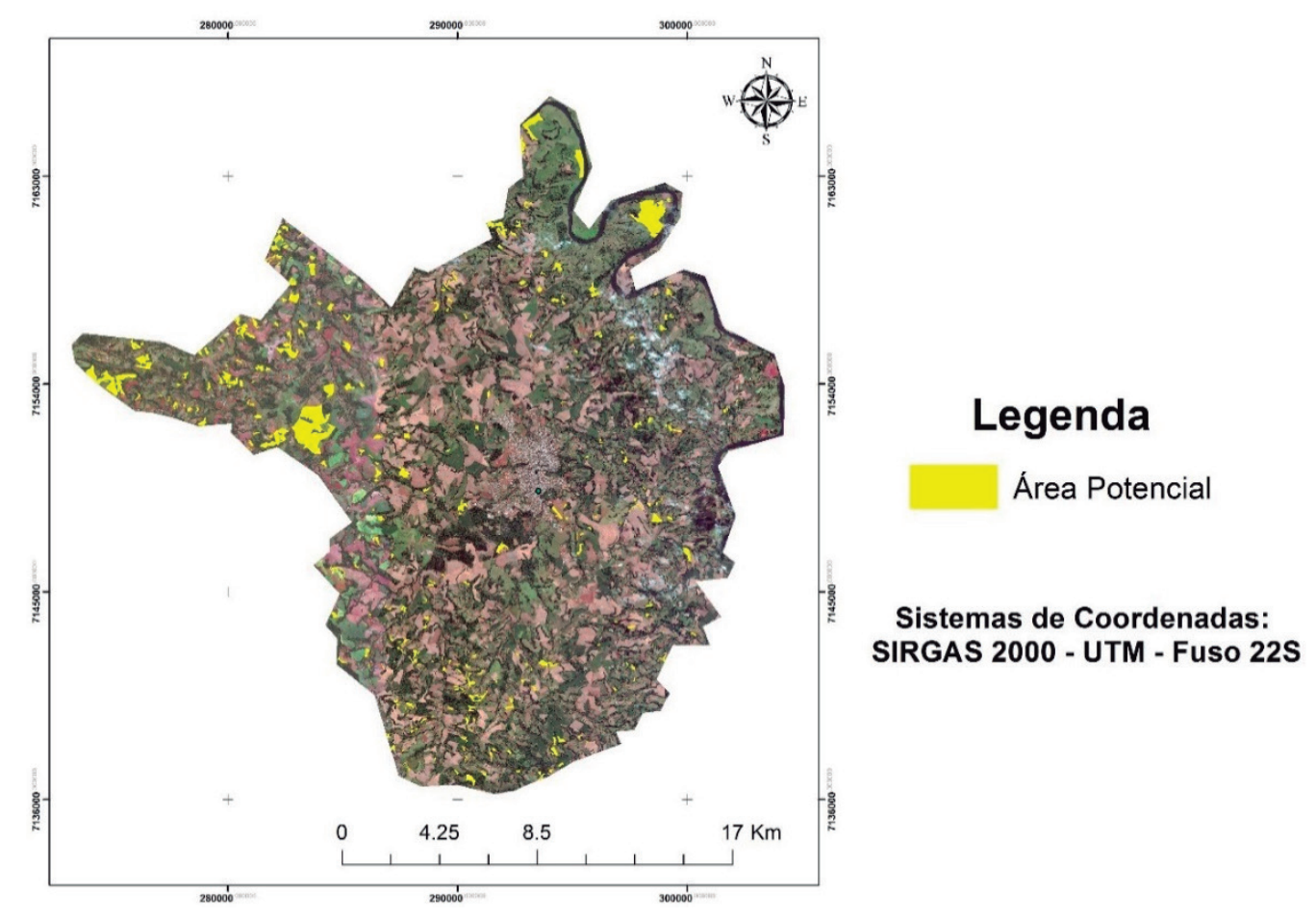

Numa classificação visando aspectos logísticos da produção florestal (Tabela 3), a separação das áreas por raios de distância e por classe mostrou que, no raio de $5 \mathrm{~km}$, a classe que apresenta maior valor é de FP-Eucalipto, com 340,02 ha, seguida de AP-Capoeira, com 66,68 ha. Na Classe FP-Pinus é possível observar que a maior concentração está no raio de $10 \mathrm{~km}$, com 47,72 ha, e a menor concentração no raio de $5 \mathrm{~km}$ (3,17 ha), diferente da FP-Erva-mate, onde a maior concentração se encontra no primeiro e segundo raios de distância, fato associado à existência de uma empresa de processamento de erva-mate que busca matéria prima em raios menores de distância da mesma. 
Tabela 3 - Áreas de plantio efetivo e com potencial de plantio, separados por classes e por distância.

\begin{tabular}{lccccc}
\hline USO DO SOLO / Raio de Distância & $\mathbf{5 ~} \mathbf{~ m}$ & $\mathbf{1 0} \mathbf{~ k m}$ & $\mathbf{1 5} \mathbf{~ k m}$ & $\mathbf{2 0} \mathbf{~ k m}$ & Total \\
\hline FP - Pinus (ha) & 3,17 & 45,72 & 25,82 & 5,69 & 80,40 \\
\hline FP- Eucalipto (ha) & 340,02 & 347,19 & 176,70 & 15,98 & 879,89 \\
FP - Erva-Mate (ha) & 16,01 & 15,51 & 4,54 & 0 & 36,06 \\
\hline AP - Capoeira (ha) & 66,68 & 218,97 & 225,35 & 41,94 & 552,94 \\
AP - Pastagem degradada (ha) & 2,68 & 312,39 & 330,63 & 165,99 & 811,69 \\
AP - Lavoura Degradada (ha) & 0,91 & 20,03 & 21,81 & 0 & 42,75 \\
Total (ha) & 429,47 & 959,81 & 784,85 & 229,6 & $2.403,73$ \\
\hline Porcentagem (\%) & 17,86 & 39,93 & 32,65 & 9,55 & 100 \\
\hline
\end{tabular}

Para a AP-Capoeira, a maior concentração encontra-se no raio de 15 km, com 225,35 ha, e a menor concentração no raio de $20 \mathrm{~km}$, ambas distantes da área urbana do município. O mesmo acontece para AP-Lavoura Degradada e AP-Pastagem Degradada, onde sua maior concentração está no raio de $15 \mathrm{~km}$. Porém, para AP-Pastagem degradada sua menor concentração está no raio de $5 \mathrm{~km}$, com 2,68 ha. AP-Lavoura Degradada não apresenta área no raio de $20 \mathrm{~km}$.

Estas áreas, quando observadas em distribuição espacial (Figura 4), mostram que a distribuição de áreas AP é maior do que a distribuição de FP, sendo suas maiores concentrações nos raios 15 e $20 \mathrm{~km}$. Para FP a maior concentração está nos raios 5 e $10 \mathrm{~km}$, próxima da área urbana e das empresas, o que facilita na logística de transporte da matéria prima (pinus, eucalipto e erva-mate).

Figura 4 - Distribuição de área plantada e área potencial, com raios de distância no município de Dois Vizinhos (PR).

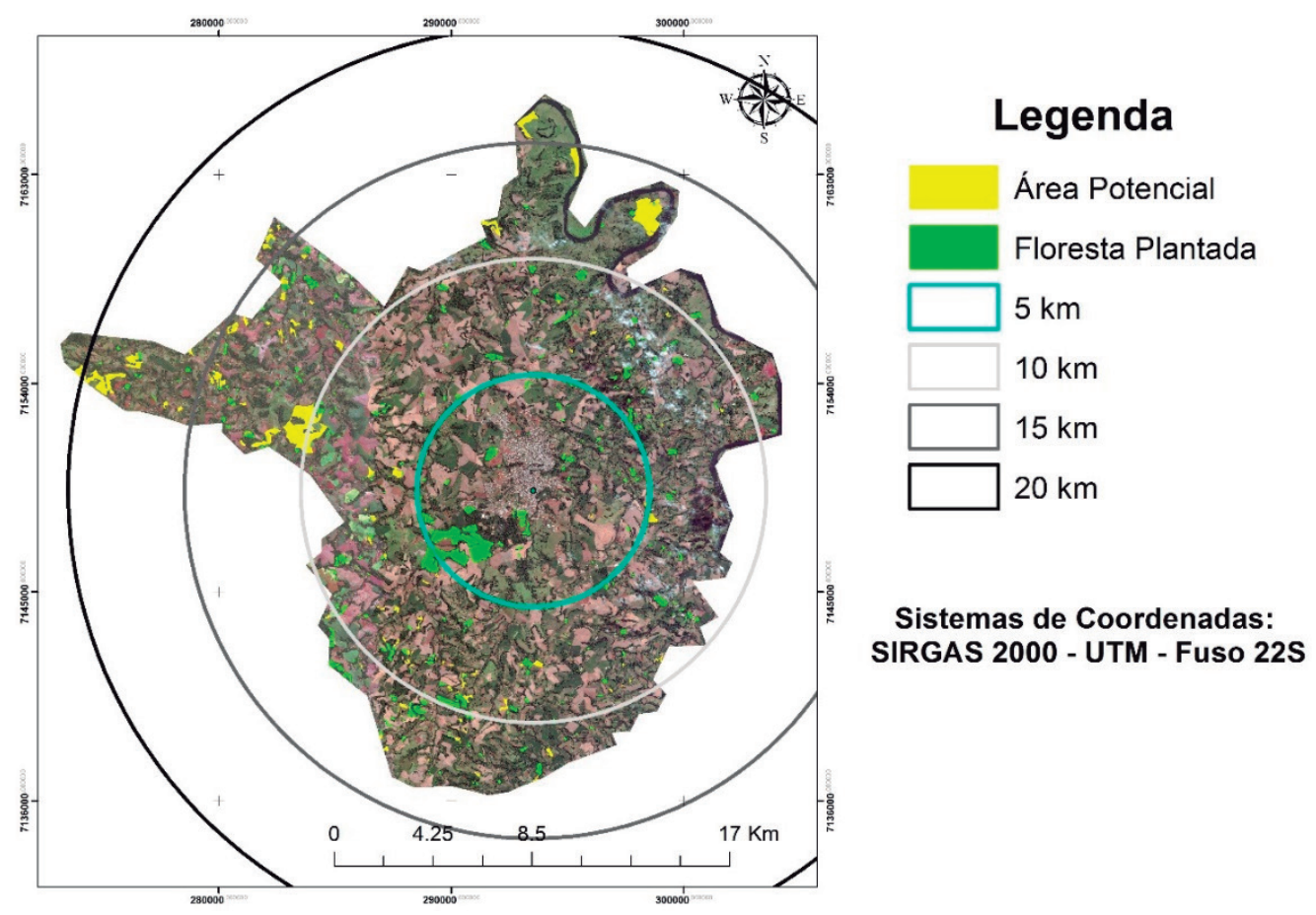


De acordo com o trabalho realizado por Bichel et al. (2014), sobre a cadeia produtiva do segmento energético de Dois Vizinhos -PR, a distância média entre o fornecedor de lenha até a empresa consumidora é de $23,58 \mathrm{~km}$. Ou seja, por conta da distância, a madeira se torna mais cara, tornando mais significativos os custos com logística, o que, por consequência, se torna uma desvantagem, por não agregar valor a nenhum do envolvidos na cadeia, somente tornando mais necessários os trabalhos de veículos de transporte desses produtos. Assim, a distância dos fornecedores até as empresas é uma das características do modelo vigente e que deve ser levada em conta na expansão da atividade.

\section{CONSIDERAÇÕES FINAIS}

Apesar da significativa área de florestas plantadas de eucalipto (879,9 ha), as mesmas têm vinculação direta, em sua maioria, com atividades agroindustriais, não estando livres para negociação de mercado entre produtor e comprador.

As áreas com florestas plantadas de Pinus são pouco significativas, havendo espaço para sua ampliação, uma vez que supririam a demanda por toras para serraria e outros usos potenciais, atualmente vindas de fora do município.

A reduzida área plantada com erva-mate mostra o desinteresse atual dos produtores pela cultura, a qual foi, em muitos casos, substituída por lavouras de culturas anuais.

Existe uma área significativa com potencial para cultivo florestal (1.407,4 ha), sem nenhuma interferência ou concorrência com áreas agrícolas e pecuárias produtivas já existentes, fato de extrema importância para o município, que pode ampliar sua geração de emprego e renda sem nenhuma substituição de atividades produtivas e inserindo novos produtores na atividade florestal.

O aproveitamento das florestas e áreas potenciais, de forma economicamente viável, em todo o território do município, deve passar por condições adequadas de logística, que compensem o investimento, mesmo nas maiores distâncias da sede ou do comprador.

Sugere-se que ações modeladas em parceria público-privada sejam realizadas, inserindo novos e atuais produtores de florestas no contexto, numa relação de longo prazo e com garantias de produção, venda e rentabilidade aos envolvidos na cadeia produtiva de base florestal.

\section{AGRADECIMENTOS}

À Secretaria Municipal de Desenvolvimento Rural, Meio Ambiente e Recursos Hídricos de Dois Vizinhos, ao Instituto de Desenvolvimento Rural do Paraná - Unidade Dois Vizinhos e à Associação Empresarial de Dois Vizinhos (ACEDV), pelo fornecimento de informações sobre as empresas e propriedades rurais do município. 


\section{REFERÊNCIAS}

ALVARES, C. A.; SENTELHAS, P. C.; STAPE, J. L. Modeling monthly meteorological and agronomic frost days, based on minimum air temperature, in Center-Southern Brazil. Theoretical and Applied Climatology. 113(3): (2017).

APRE - ASSOCIAÇÃO PARANAENSE DE EMPRESAS DE BASE FLORESTAL. Estudo Setorial APRE 2020. Curitiba: APRE. 2020. 92 p. [Acesso em: 15 mai. 2021]. Disponível em: https:// bit.ly/3gygHRu.

BICHEL, A.; NUNES, E. M. A.; BRUN, E. J. Forest expansion by forest fomentation program in Dois Vizinhos, Brasil. Anais. IV Congresso Forestal Argentino y Latinoamericano. Posadas, Misiones. (2014).

BICHEL, A.; NUNES, E. M. A.; IORIS, E. W.; BOLSAN, R. C.; BRUN, E. J. Cadeia Produtiva do Segmento Energético no Município de Dois Vizinhos - Paraná. Anais. IV Seminário de Extensão e Inovação da UTFPR. 2014.

BRASIL. Resolução n ${ }^{\circ}$ 1, de 31 de janeiro de 1994. Diário Oficial da República Federativa do Brasil.

Conselho Nacional do Meio Ambiente. Brasília. 02/02/1994. p. 07.567-07.568, 1994.

BRUN, E. J.; Demandas e oportunidades de mercado para o setor florestal madeireiro de Dois Vizinhos-PR. Dois Vizinhos: UTFPR-DV. Relatório Final de Projeto de Extensão Universitária (Edital ProExt 2014 - SESU/MEC). 2016. 37 p.

COUTINHO, V. M.; CORTE, A. P. D.; SANQUETTA, C. R.; HENTZ, A. M. K.; EISFELD, R. L.; NASCIMENTO, F. A. F. Mapeamento das áreas plantadas com Eucalyptus spp. no estado do Paraná. BIOFIX - Scientific Journal, Curitiba. v. 2, n. 1: 32-43. (2017).

SANTOS, H. G. Sistema brasileiro de classificação de solos. Brasília, DF: Embrapa, 2018.

EMBRAPA - Empresa Brasileira De Pesquisa Agropecuária. Mapeamento e estimativa da área urbanizada no Brasil. [Acesso em: 08 mai. 2016]. Disponível em: https://bit.ly/2S1sxu3. 
GORENSTEIN, M. R.; F. C. BECHARA; D. A. ESTEVAN; A. S. SGARBI \& J. C. GALlO. Estrutura e diversidade da comunidade arbórea na trilha ecológica da UTFPR, Campus Dois Vizinhos através do método de quadrantes. Anais. IV SSPA Seminário de Sistemas de Produção Agropecuária. Dois Vizinhos, PR. 2010.

HENTZ, Â. M. K. et al. Estimating forest uniformity in Eucalyptus spp. and Pinus taeda L. stands using field measurements and structure from motion point clouds generated from unmanned aerial vehicle (UAV) data collection. Forest systems, v. 27, n. 2, (2018). p. 1.

IBÁ - Indústria Brasileira de Árvores. Relatório Anual 2016. [Acesso em: 12 dez. 2017]. Disponível em: https://bit.ly/3gudH8Q.

IBÁ - Indústria Brasileira de Árvores. Sumário Executivo 2018. [Acesso em: 09 jan. 2018] Disponível em: https://bit.ly/3vB86Su.

IBÁ - Indústria Brasileira de Árvores. Relatório Anual 2020. [Acesso em: 12 mai. 2021]. Disponível em: https://bit.ly/3wwwLJm.

IBGE, INSTITUTO BRASILEIRO DE GEOGRAFIA E ESTATÍSTICA. Dois Vizinhos - PR. Disponível em: https://bit.ly/3vxB3yA. Acesso em: 13 de fev. de 2018.

IPARDES - Instituto Paranaense de Desenvolvimento Econômico e Social. Caderno Estatístico do estado do Paraná 2013. [Acesso em: 28 fev. 2017]. Disponível em: http://www.ipardes.gov.br.

JUVENAL, T. L.; MATTOS, R. L. G. O setor florestal no Brasil e a importância do reflorestamento. BNDES Setorial. 2002.

MAAK, R. Geografia física do estado do Paraná. Curitiba: Banco de desenvolvimento do Paraná, 1968. $350 \mathrm{p}$.

EISFELD, R. DE L.; NASCIMENTO, F. A. F. DO. Instituto de Florestas do Paraná: Mapeamento dos Plantios Florestais do Estado do Paraná - Pinus e Eucalyptus. 2015.

MOTA, CLÉZIO JOSÉ. Diagnóstico Ambiental das Margens do Córrego Lagoa da Santina visando Estratégias para Plano de Recuperação [Monografia]. Dois Vizinhos: Universidade Tecnológica Federal do Paraná; 2015. 
PAIVA, H. N.; JACOVINE, L. A. G.; TRINDADE, C.; RIBEIRO, G. T. Cultivo de eucalipto: implantação e manejo, Viçosa, MG: Aprenda fácil, 2011. 354 p.

PIGOSSO, D. B.; FARIAS, E.; BECEGATO, V.; ONOFRE, S. B. Diagnóstico ambiental da Bacia Hidrográfica do Rio Jirau Alto - Dois Vizinhos - PR. Revista Geoambiente Online. (2009).

PORTAL DOIS VIZINHOS. Dados do Município. [Acesso em: 28 fev. 2017]. Disponível em: https:// bit.ly/3wBw5m2.

ROCHADELLI, R.; SILVA, J. C. G. L. DA.; RODRIGUES, F.; SCHNEIDER, A. V.; PETLA, D. Expansão Florestal via fomento no segundo planalto paranaense: uma abordagem a partir da estrutura fundiária das propriedades rurais da região. Cerne. 14(2): 163-169. (2008).

SCHUMACHER, M. V.; CORRÊA, R. S.; VIERA, M.; ARAÚJO, E. F. DE. Produção e decomposição de serapilheira em um povoamento de Eucalyptus urophylla x Eucalyptus globulus maidenii. Cerne. 19(3): 501-508. (2013).

SOUZA, J. T. DE. Qualidade da madeira serrada proveniente de árvores dominantes e médias de Eucalyptus grandis. Cerne. 18(1): 167-174. (2012).

TATAGIBA, S. D.; PEZZOPANE, J. E.; REIS, E. F. DOS. Fotossíntese em Eucalyptus sob diferentes condições edafoclimáticas. Engenharia na Agricultura. 23(4): 336-345. (2015).

TREVISAN, R. Efeito do desbaste nos parâmetros dendrométricos e na qualidade da madeira de Eucalyptus grandis W. Hill ex Maiden, [Tese de Doutorado]. Santa Maria: Universidade Federal de Santa Maria; 2010. 